\title{
VIVENCIA DEL SENESCENTE AL INTERIOR DE UNA CULTURA SECULARIZADA.
}

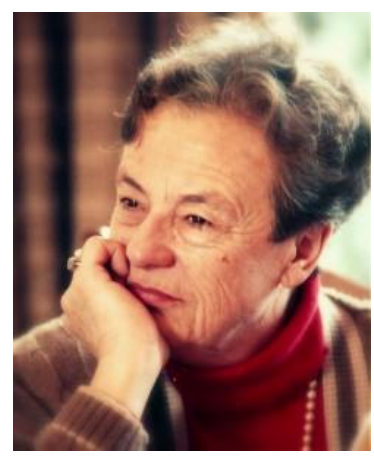

Ana Escríbar Wicks

Filósofa. Es Profesora titular de la Facultad de Filosofía y Humanidades de la Universidad de Chile. Ex presidenta de la Sociedad Chilena de Filosofía, llega a ser directora del Departamento de Filosofía y del Centro de Estudios de Ética Aplicada (CEDEA). Recibe la Medalla al Mérito Académico "Rector Valentín Letelier". Actualmente, como Profesora Emérita de la Facultad de Filosofía y Humanidades de la Universidad de Chile,

\section{Introducción.}

Como Uds. pueden constatar con solo mirarme, yo pertenezco al grupo de los adultos mayores, sector etario cada vez más numeroso en nuestro país, cuya condición dentro de nuestra cultura centrará la presente reflexión.

Vivo hace desde hace tres años en una residencia para dicho grupo y durante este período he participado con interés y dedicación en algunas de las numerosas actividades ofrecidas allí a los senescentes. Esta participación me ha permitido observar con calma - desde la perspectiva de mi especialidad que es la filosofía y centralmente la ética - no solo lo referente a mi propia vivencia, sino también a la de un buen número de residentes; de manera que mi presentación no será la de una especialista en el tema, sino que tendrá más bien un carácter testimonial.

La exposición tenderá a mostrar la vivencia que tiene de sí mismo el senescente al interior de una cultura secularizada, como es aquella en la que nos ha correspondido vivir; vale decir, una cultura en la que los asuntos de interés público se han independizado de la regulación religiosa y la creencia en un más allá en el que se prolongue la vida después de la muerte - otorgándole -sentido es solo materia de fe para algunos grupos, a menudo minoritarios.

Iniciaré, pues, mi exposición con una reflexión sobre nuestra cultura revisando brevemente sus raíces, compartidas por toda la cultura occidental; esas raíces se remontan a la filosofía griega, pero también a los textos bíblicos judeo - cristianos, representativos de la religiosidad de cuya tutela en la actualidad esta cultura se habría supuestamente independizado.

Espero poder mostrar con ello de pasada que, si bien la secularización es una exigencia de la democracia en pro de la igualdad ante la ley de creyentes y no creyentes, ella no implica necesariamente el rechazo del reconocimiento de los aportes recibidos de la fe religiosa; más bien lo exige, aunque su interpretación va variando a lo largo del recorrido.

Una última observación antes de empezar el desarrollo de nuestro tema; el título, puede interpretarse en un doble sentido: el de la vivencia que el senescente tiene de sí mismo y aquella que 
de él tiene nuestra cultura; desarrollaremos primero este segundo aspecto, porque pareciera que él influye poderosamente sobre el primero.

\section{La cultura occidental: su aspiración originaria y su contradicción histórica}

\subsection{El concepto de cultura.}

Toda cultura puede ser considerada como una narración que esboza un modo posible de ser humanos en el mundo, vale decir, como un proyecto de humanidad; dicho proyecto resulta necesario para el hombre, porque él - a diferencia del resto de los animales que nacen definidos por el instinto - debe descubrir lo que le exige y lo que le entrega su condición para llegar a ser lo que es; vale decir, para llegar a ser humano. Así, el adulto mayor que - al igual que todos los hombres ha nacido y vive dentro de una cultura, está marcado por el modo de ser que ella implica, está instruido por sus valores, e influido por sus contradicciones.

Un gran filósofo francés contemporáneo, Paul Ricoeur, del que confieso ser discípula, nos dice que si efectivamente consideramos la cultura como una narración que esboza un modo posible de ser humanos en el mundo, deberemos tener presente que toda narración es susceptible - por lo menos de dos interpretaciones; una que para explicar el fenómeno del que se trata, en este caso la cultura, se remonta a su génesis, la otra que intenta explicarlo en función de la meta hacia la que ella tiende; ambas, por otra parte, pueden dar lugar a lecturas diferentes. Consecuentemente, deberemos tener presente que la interpretación de la cultura que ahora iniciamos es una entre varias posibles.

Paul Ricoeur tiene entre sus obras un pequeño librito, "Educación y Política", cuyo capítulo $2^{\circ}$ se titula "La vida, un relato en busca de narrador". La tesis que subyace en el desarrollo de dicho capitulo - y que haremos nuestra - es la siguiente: la vida de cada cual puede ser un conjunto azaroso de sucesos que acontecen sin orden ni concierto desde el nacimiento hasta la muerte; o bien - si el que la vive logra constituirse en narrador de lo que es su propia historia - ella puede llegar a ser un relato dotado de sentido.

A esa tesis y siendo fieles a lo que está implícito en ella, nosotros añadiremos que solo entonces vivimos efectivamente nuestro propio modo de ser humanos en el mundo. Porque este animal que es el hombre únicamente descubre el auténtico significado de lo humano esforzándose por llegar a serlo; y ese descubrimiento exige la respuesta - que resulta variable y nunca definitiva - a una inquietud fundamental: aquella que busca el sentido de la existencia, expresada en una persistente interrogación arqueológica y teleológica; esto es, en relación con el origen y la meta de su vida.

Dicha inquietud adquiere una urgencia especial en el caso del adulto mayor dentro de una cultura secularizada; porque la búsqueda implicada en esa doble interrogante dirige siempre la mirada hacia un futuro - que para ella como producto de la secularización necesariamente es terrestre - en el que se estima que se cumpliría la meta otorgadora de sentido. Pero el senescente sabe que el cierre de su narración se aproxima, de modo que casi podría decirse que carece de futuro. Consecuentemente, para que pueda descubrir, o incluso profundizar su percepción de ese sentido habría que buscar una meta que trascienda su propia desaparición.

\subsection{Aspiración.}


Nuestras modernas sociedades pluralistas - en las que hasta el momento ha culminado la evolución cultural, social y política occidental - aspiran a que cada uno de sus miembros, a pesar de sus diferencias de todo tipo, llegue a compartir una condición común, la de ser "ciudadano" del Estado en el que todos conviven.

Esta aspiración se expresa ya claramente en el lema de la Revolución Francesa, "Libertad, Igualdad, Fraternidad"; en ese momento se pensó que esos derechos políticos otorgaban a cada uno la "autonomía" o independencia suficiente para ser a la vez legislador y súbdito; vale decir, para participar eficazmente en el ejercicio del poder o, por lo menos, en la elección de quienes lo ejercerían en representación suya y para acatar - sin que ello significara un sometimiento - las leyes emanadas de ese ejercicio para regular la convivencia.

Pero el transcurso de los siglos mostró que esos derechos políticos no bastaban para el logro de la condición ciudadana; que había que incluir además los derechos socio - económicos, culturales, medioambientales, etc. Se configura así la noción actual de los "derechos humanos", cuyos fundamentos se remontan hasta los conceptos de "ciudadanía" de la filosofía griega y de "prójimo", propio de la concepción judeo - cristiana de las relaciones entre los hombres.

Para la primera, la ciudadanía se traducía en la participación directa en el gobierno, pero se trataba de un derecho de los griegos al interior de la polis; para el segundo, en cambio, la comprensión de Dios como Padre implicaba la condición de hermanos de todos los miembros de la humanidad.

Esa igualdad - implicada en la diversidad de los hermanos - constituye el fundamento de la norma sapiencial "no hagas a otro lo que no quisieras que se te hiciese" y ésta puede ser considerada como enunciado negativo del mandamiento de amar al prójimo como a sí mismo. Dicha norma, reconocida actualmente como "Regla de Oro" de la ética occidental, posee de partida un sentido que se ha ido explicitando paulatinamente a lo largo de la historia, y me atrevo a afirmar que representa el núcleo de la narración constitutiva de nuestra cultura.

\subsection{Contradicción inherente a la cultura occidental}

El enunciado de esa norma sapiencial - así denominada porque es transmitida por la tradición sin que forme parte textualmente ni de las leyes cívicas ni del decálogo judeo-cristiano - se ha mantenido sin alteraciones a lo largo de milenios; sin embargo, lo que cada uno no quisiera que se le hiciese se ha ido llenando de nuevos contenidos, a la vez que se ha ido ampliando el concepto del "otro" - vale decir, del prójimo - desde la referencia al cercano en el espacio y en el tiempo hasta la inclusión de la humanidad completa. Más aún, en la actualidad se está llegando - en alguna medida y por lo menos en teoría - a ver en ese "otro" que deberíamos respetar como a nosotros mismos a todos los seres vivos e, incluso, a la naturaleza en su conjunto, puesto que de ella depende la preservación de la vida humana.

En esta forma, pareciera que se ha ido forjando una "cultura" - un modo de ser en el mundo - que va descubriendo poco a poco el contenido de una meta, implícita de partida en sus tradiciones: el establecimiento de relaciones filiales entre todos los hombres y de estos hacia los elementos que configuran no solo la tierra, sino el cosmos completo, como único medio de mantener en el mundo la presencia de una "humanidad auténtica". 
Sin embargo, desde los inicios de la modernidad, junto con el creciente reconocimiento de esa meta, parece profundizarse la percepción de un recorrido que contradice ese supuesto avance lento y accidentado hacia su logro. Esta contradicción se hace evidente - por ejemplo - a comienzos del S. XX, en la obra de Nietzsche. Se anuncia allí la llegada de un huésped aterrador, que el filósofo alemán llama "nihilismo" y que trae consigo una sola y trágica convicción: la de una carencia absoluta de sentido de la vida. Esta última, afirma, es en sí misma una fuerza gozosa que se basta para auto celebrarse, pero la razón humana - enfrentada a su propia caducidad - busca un sentido que la explique y la compense. Porque el hombre, ese animal increíblemente valiente - añade Nietzsche - puede soportarlo todo, excepto el sinsentido de su existencia.

En respuesta a esa búsqueda habrían aparecido las religiones, la filosofía y, por último, la ciencia experimental; esta última - sin embargo - cuestionó los enunciados provenientes de las dos primeras en lo referente a un posible sentido de la vida, planteando que el carácter no verificable racional o empíricamente de dichos enunciados los priva de la validez universal a la que aspiran.

Ahora bien, ¿aportan la ciencia y la técnica una respuesta válida para esa exigencia humana de sentido? Al respecto ya Kant en el S. XVIII nos dice que la razón humana no puede satisfacerla; sin embargo - añade - la naturaleza misma de la racionalidad, con su irrenunciable interrogar arqueológico y teleológico, impide al hombre dejarla de lado, a pesar de la impotencia señalada.

Cabe entonces preguntarse: ¿es insuperable esta contradicción entre la necesidad de sentido y la imposibilidad de alcanzarlo que parecería inherente a nuestra cultura y que haría inútil su búsqueda?

\subsection{Posible superación de esa contradicción y sus efectos.}

La historia nos muestra que en la evolución cultural de Occidente se da, efectivamente, la aspiración al logro de una humanidad integral para cada hombre, como meta de un proceso hacia el cual - a pesar de las frecuentes caídas y de los horribles retrocesos - podría pensarse que ella avanza.

Si se reconociera en la búsqueda del cumplimiento de esa aspiración un posible sentido para la vida humana - sin proyectarlo necesariamente como meta de la evolución biológica y cosmológica anterior - no habría contradicción con las tesis científicas de una evolución azarosa previa a la aparición del hombre. Se podría afirmar, entonces, que es su racionalidad la que parece introducir en el cosmos la presencia de la teleología y lo hace solo en relación con el ser humano mismo y con su propia obra.

El reconocimiento de esta meta humana posibilitaría la definición del "bien común" como humanización de la convivencia al interior de una sociedad; ello permitiría que - en las sociedades democráticas - los procesos educativos no se limitaran a la instrucción científico-técnica de niños y jóvenes, sino que tendieran también a formarlos axiológicamente; por lo menos, en el reconocimiento respetuoso de una diversidad - que incluye entre muchos otros aspectos - las sucesivas etapas del desarrollo de la vida humana: niñez, juventud, madurez y ancianidad.

\section{Consideración del adulto mayor al interior de una cultura secularizada.}

\subsection{La valoración instrumental.}


¿Existe actualmente en esta cultura que hemos estado describiendo un reconocimiento del "otro", vale decir por ejemplo del anciano?

Lo que hoy se valora fundamentalmente parece ser el aporte de cada uno al progreso derivado del desarrollo económico; porque este último - absolutamente válido como medio al servicio de una vida auténticamente humana - se nos ha ido instalando en forma paulatina como única meta de la humanidad. Vale decir, hoy se valora fundamentalmente al hombre que cumple una función útil para sí mismo y para el conjunto.

Se olvida con ello que la utilidad es una categoría adecuada para la definición de los instrumentos al servicio de la humanidad, pero no para la valoración del ser humano mismo; este último - como lo afirma el Imperativo Categórico enunciado por Kant - es el único ente que debe ser tratado siempre como un fin y nunca solamente como un medio, vale decir, jamás solo como algo útil para el logro de un fin determinado.

Ahora bien, los senescentes generalmente ya no hacen ese aporte al progreso económico; porque los llaman al retiro leyes gestadas cuando la vida no tenía la duración que hoy detenta y la decadencia física y psíquica se iniciaba más temprano, o porque efectivamente han perdido ya la capacidad de desempeñar esa función. Se convierten, entonces, en una carga que - con la prolongación de la vida y la tasa decreciente de nacimientos - resulta cada año más onerosa para la comunidad. De acuerdo con este parámetro, la presencia del senescente no puede, pues, resultar positivamente valorada.

Consecuentemente, nuestras modernas sociedades democráticas - que están empezando a reconocer como "otro" - vale decir, como merecedores de respeto - a las especies animales y vegetales, no han descubierto plenamente aún la condición del senescente como "otro"; no han comprendido que el respeto del derecho del senescente a completar la narración de su vida como una historia dotada de sentido está implícito en ese "no hagas al otro lo que no quisieras que se te hiciese"; y más aún, que ese derecho podría dar lugar al apuntar complementario que ayudaría a preservar la percepción positiva de un sentido de la vida de quien - como el senescente - ve aproximarse el cierre de su narración.

Esta ausencia de una valoración positiva del senescente se pone de manifiesto en múltiples aspectos que - frecuentemente - aunque no son percibidos por la comunidad, afectan la vivencia que él tiene de sí mismo.

Así, por ejemplo, el actual concepto de familia en la práctica no lo incluye, como lo muestra el hecho de que el espacio dentro de las casas de sus hijos no lo contempla; el trabajo y las distancias no les deja tiempo a estos últimos para acompañarlo con frecuencia y a sus nietos y bisnietos los ve de vez en cuando; a menudo su "pensión" no le alcanza para vivir adecuadamente, la atención de su salud es deficiente, los medicamentos suelen quedar más allá de su poder de compra, no se ofrecen tareas o diversiones en las que pueda y le resulte atractivo participar, ni instituciones concordantes con el monto de las pensiones que recibe, en las que pudiera vivir digna y agradablemente.

Ante esta realidad, el senescente no puede menos que sentirse postergado, rechazado; llega a convencerse de su propia inutilidad y siente que su vida entera - mirada desde este último tramo carece del sentido que en algún momento pudo quizás atribuirle. El recuerdo de los años pasados - 
incluso de los acontecimientos positivos - le resulta penoso; porque - dada la condición en la que han desembocado - en lugar de alegrarse por haberlos vivido, lamenta que hayan quedado atrás.

Si se interroga a los residentes de una Institución especializada - incluso en aquella en la que yo vivo que es de excelencia - si ellos decidieron libremente internarse, la respuesta es negativa; dicen haber sido obligados a hacerlo. ¿Significa ello que el bienestar del senescente exigiría que no vivieran en Instituciones especiales para ellos? No necesariamente.

El terapeuta ocupacional - que se desempeña donde yo vivo - explicita lo que una Institución especializada puede ofrecer al senescente; como todo ser humano, este necesita - dice - tener alguna ocupación con significado para él mismo y para el contexto cultural en el que la ocupación se desarrolla; la selección de esas actividades - añade - debe centrarse en las capacidades preservadas y teniendo en cuenta la historia de vida y las aficiones e intereses de cada cual. Resulta, pues, indispensable, junto con restar importancia a sus actuales limitaciones, reunir información de la historia de vida de cada senescente, de sus aficiones e intereses.

Así, lo que el bienestar de senescente exige es el reconocimiento de su condición de "otro"; esto es, el reconocimiento de que no debemos hacerle lo que no quisiéramos que se nos hiciese, ya sea con el recurso a una institución especializada que los recibiera en forma permanente o en ciertas horas del día si es necesario, o sin ese recurso si no lo es.

\section{Posibles efectos complementarios del reconocimiento del senescente como un "otro" al interior de una cultura secularizada.}

El descubrimiento del senescente como un "otro" a quien no debiéramos hacer lo que no quisiéramos que se nos haga, nos lo muestra como sujeto del derecho a ser el narrador de su propia historia hasta su cierre natural; y este límite puede ponerlo no solo la propia muerte, sino también la pérdida de las capacidades para continuar la propia narración.

Pero ese descubrimiento puede, por otra parte, ser el umbral de un camino conducente a la comprensión de que hay otros "otros" - nietos y bisnietos de los actuales senescentes - a quienes tampoco deberíamos hacer lo que no quisiéramos que se nos hubiera hecho; esto es, dejarles como herencia una tierra no apta para una vida auténticamente humana.

Así, el respeto al pasado implicado en la preocupación por los ancianos desemboca inevitablemente en el respeto del futuro, en el que los adultos de hoy serán los senescentes para los que hoy son los nietos y bisnietos de los actuales ancianos. El reconocimiento de los derechos del senescente puede, pues, representar un aporte para un aspecto no trabajado en esta interpretación del sentido de la narración que es nuestra cultura.

La "Regla de Oro", no hagas a otro lo que no quisieras que se te hiciese, exigiría - junto con el respeto al pasado hecho presente por los actuales senescentes - la preocupación por el futuro, expresada en el cuidado de la tierra en la que conviven pasado, presente y futuro de una humanidad que - al interpretar sus propias tradiciones - va quizás descubriendo poco a poco un posible sentido de la vida. 